\title{
Insight Into Invasive Species (Mikania micrantha), Its Control Measures and Programmes in Nepal
}

\author{
Rajan P. Paudel ${ }^{1}$ \\ Email : rajanpoude1093@gmail.com
}

\begin{abstract}
Invasive species adversely affects the ecology and habitat of the species existing in a particular region. They are one of the top threats to the biodiversity of life on Earth. Mikania micrantha is spreading like a wildfire in Nepal whose effect on Rhino habitat is being studied in Chitwan National Park. Various mechanical, chemical and biological methods of control for Mikania are available. It's likely to be more cost effective to prevent the spread of invasive species in the first place than to tackle the biodiversity crisis once they have become established.
\end{abstract}

Keywords: Invasive species, Mikania, Control, Habitat

\section{What are Invasive Species?}

Invasive species refers to the non-native (exotic) species of plants or animals that adversely affects the ecology and habitat of the species existing in a particular region. The species based mechanism of classifying species as invasive focuses on the competition while the Ecosystem based mechanism focuses on the impact on the nature, composition and utilization of resources of a habitat. Invasive species often coexist with native species for an extended time, and gradually the superior competitive ability of an invasive species becomes apparent as its population grows larger and denser and it adapts to its new location in absence of their natural predators.

\section{What is the Global Scenario?}

The international team of investigators who wrote the Global Invasive Species Programme report documented a total of 542 species acting as invasive aliens - 316 plants, 101 marine organisms, 44 freshwater fish, 43 mammal, 23 bird and 15 amphibian species. Of the 57 countries assessed, they found that, on average, there are 50 non-indigenous species per country which have a negative impact on biodiversity (Environment News Service, 2010). There are continuous reports of species being invasive and affecting the country's indigenous species. Many countries around the world have kept Invasive species as a major threat to their Natural Resource Management.

\footnotetext{
${ }^{1}$ Student, Kathmandu Forestry College
} 


\section{What about in Nepal?}

It may be difficult to find the exact database of the species that are invasive to Nepal. Some biotic species that are termed invasive and mostly heard are Banmara ( Lantana spp.), Mikanaia ( Mile-a-minute, Mikania micrantha) Jalkumbhi ( Water Hyacinth), Chromolaena odorata, Eichornia spp . Banmara is the most popular invasive species and it was attributed to be a major factor in the forest habitat destruction of many parts especially in the mid hills. Water Hyacinth and Echornia spp are the major cause of wetland habitat destruction in Nepal. At present Mikania has come as a headache to the conservationist, farmers and forest managers.

\section{Mikania micrantha (Mile-a Minute; Lahare Banmara)}

\section{Introduction:}

Mikania was first reported in Ilam district in 1966, while its presence was reported in Chitwan in 2000, but during the 2008 rhino census, it was found that the plant spread like wildfire in the national park area (Bhushal Ramesh Prasad, 2010).

Mikania micrantha is a perennial creeping climber known for its vigorous and rampant growth. It is branchy, slender-stemmed perennial vine. The leaves are arranged in opposite pairs along the stems and are heart-shaped or triangular with an acute tip and a broad base. Leaves may be $4-13 \mathrm{~cm}$ long. The flowers, each $3-5 \mathrm{~mm}$ long, are arranged in dense terminal or axillary corymbs (Yadav Nagendra Prasad, 2010) .Flowering starts in August and continues up to January. Fruit setting occurs between September and February, initiated 17 -21 days after flowering. Single stalks of Mikania can produce20, 000 - 40,000 mature seeds in one season. The seed is black, linear-oblong, five-angled and about $2 \mathrm{~mm}$ long. Each seed has a terminal pappus of white bristles that facilitates dispersal by wind or on the hair of animals.

\section{Description:}

Division: Magnoliophyta

Order: Asterales

Family: Asteraceae

Botanical Name: Mikania micrantha

Common Name: American rope, Chinese creepe (English); Lahare Banmara (Nepali)

Distribution: Widespread in Asia and the Pacific, Australia and South, North and Central America

Habitat: Wet places, forest borders and clearings, along the banks of streams and rivers, roadsides and railway tracks, in pastures, forest plantations, agricultural and agro - forestry systems, open disturbed areas and barren lands. Mikania grows luxuriantly on leached and nutrient poor sandy loam to clayey soils. Being a C 3plant, Mikania can produce a 
large quantity of biomass in a single life span. Heavy grazing and browsing promotes the spread of Mikania into new ecosystems. The weed cannot tolerate shade and hence fails to penetrate undisturbed natural forest areas.

Mode of infestation: Mikania can smother, penetrate crowns and choke and pull over plants. It thus causes a significant reduction in the growth and productivity of several crops. Retardation of tree growth in Mikania-infested plantations is attributed to production of allelopathic substances by it.

(Source: Invasive Pest Fact Sheet, APFISN)

\section{Why are they on tip of every body's tongue?}

The invasive species are mostly characterized with:

- The ability of rapid reproduction both sexually and asexually

- The tremendous capability of establishing themselves in a new place

- Tolerance of wide range of environments

- Phenotypic plasticity (the ability to alter one's growth form to suit current conditions )

- Dominating the native species in competition

- Fast growth and

- High dispersal ability

With these traits as backup, they are jeopardizing global biodiversity by out-competing native species for resources such as nutrients, light, space, moisture and food; altering ecosystem functions; nutrient cycling and hydrology in native ecosystems, and changing ecological relationships among native species. Invasive species that are closely related to rare native species have the potential to hybridize with the native species. Harmful effects of hybridization can lead to a decline and even extinction of native species. This peculiar temperament makes them one of the top three threats to the biodiversity of life on Earth.

\section{Is not there any solution?}

The Invasive Pest Fact Sheet on Mikania published by Asia - Pacific Forest Invasive Species Network lists out the following control measures as a solution:

Mechanical: Sickle weeding, uprooting and digging are the main mechanical control methods in practice. Sickle weeding before flowering and seed setting gives temporary control. Uprooting during the initial stages of growth is the most effective mechanical control method. The slash and burn technique is also practiced widely. One advantage of this method is that it reduces the vegetative propagation of Mikania.

Chemical: Both pre-emergent and post-emergent herbicides are generally used for Mikania control. Pre-emergence application of Oxyflourfen $(0.06 \mathrm{~kg}$ ha- 1$)+\operatorname{Paraquat}(0.24 \mathrm{~kg}$ ha1 $)$ 
is reported to be effective if applied before flowering or seed setting. Glyphosate is widely used in many countries against Mikania, especially in forest plantations. The dosage used varies widely depending on the intensity of infestation and number of applications required for effective control. Herbicides Triclopyr +Picloram (commercial name Grazon DS) @ 1.751 ha-1 and Triclopyr (commercial name Garlon 600)@ $500 \mathrm{ml}$ ha-1 also gives excellent control of Mikania.

Biological: Biological control using a natural insect enemy, viz., Liothrips mikaniae from Trinidad, was attempted in the Solomon Islands and Malaysia but successful establishment was not achieved. Recent studies carried out by CABI Bioscience (UK) in collaboration with Kerala Forest Research Institute (India) and institutions under the Indian Council of Agricultural Research have shown that a highly damaging microcyclic rust,viz., Puccinia spegazzinii, which naturally occurs and causes damage to Mikania in the neotropics, has great potential as a bio-control agent against the weed.

A research study done in Kerala and published in Journal of Tropical Agriculture has identified 19species of insect pests and a species of mite belonging to 15 families that could cause different extent and nature of damage to the Mikania. Among them tea mosquito bug (Helopeltis theivora) caused serious damage on Mikania. However their biological use can be limited by the fact that all of these pests are polyphagus in nature (Journal of Tropical Agriculture, 2002).

\section{What is being done in Nepal?}

Research study is being carried out in Chitwan, for the first time in Nepal, whether an

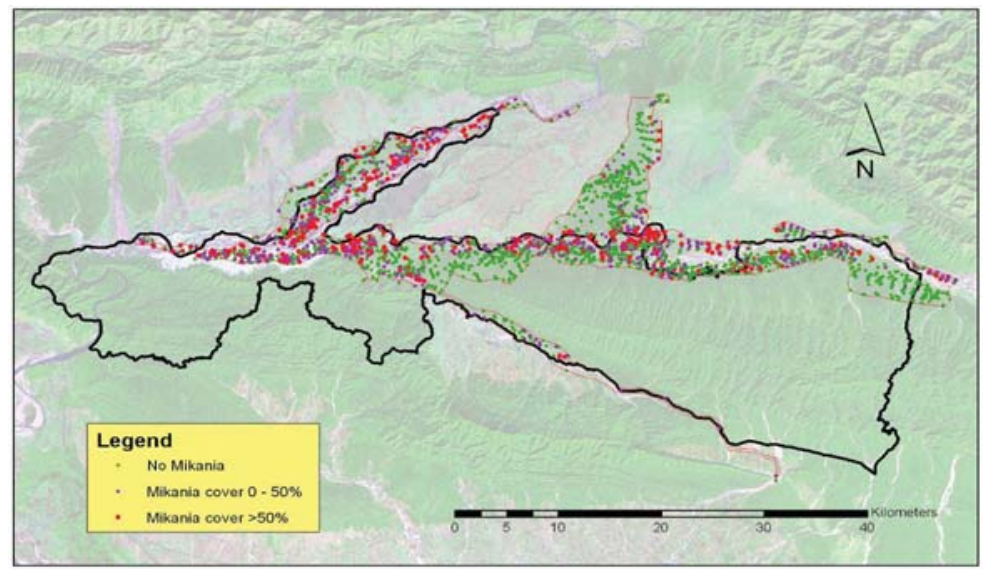

Fig1. Picture showing distribution of Mikania in Rhino habitat in Chitwan National Park; note the darker point's showing high Mikania presence (Source: Naresh Subedi, NTNC, Chitwan) 
invasive plant species Mikania micrantha (Mikania Jhar) that is spreading at an alarming rate in the Park has any impact on the rhino population there. The Rhino was chosen for the research because, it being the indicator species, the first impact of the ecosystem degradation falls on the species.

The initial findings have shown that the density of Mikania is high in the place which has been frequently used by the Rhino as its habitat. This may have a serious impact on the part of habitat management and monitoring of wildlife. The research findings are expected to greatly help in the conservation efforts.

\section{Conclusion}

The effect of invasive species can be deleterious. Various mechanical, chemical and biological methods of control are available; however, extensive research on their biology and ecology needs to be done before any application. Several community forests in Nepal are also affected by this weeds which can be eradicated through user participation. If proper management is not done in time they may invade most of the habitat and pose threat to the biodiversity and wildlife habitat. Though direct economic cost through production loss and management cost of invasive may seem to be less but, if monetary values are assigned to the extinction of species, loss in biodiversity, and loss of ecosystem services, costs from impacts of invasive species would drastically increase. It's likely to be more cost effective to prevent the spread of invasive species in the first place than to tackle the biodiversity crisis once they have become established.

\section{References}

Invasive Pest Fact Sheet, Mikania micrantha, Mile-a-minute weed; Asia - Pacific Forest Invasive Species Network.

Abraham et.al. 2002.Natural Enemies on Mikania micrantha H.B.K. in Kerala, India. Journal of Tropical Agriculture 40: 39-41.

Bhushal, R.P. Study to ascertain invasive plant impact on Chitwan Park, The Himalayan Times, 2010-04-05

Winning Battles but Losing the War on Invasive Alien Species; Environment News Service, February 4, 2010.

Prasad,Y.P. How Mikania micrantha (Lahare banmara) destroy the forest and agricultural crops in residential area of Nepal? ; Nepal Forestry website, 2010

www.wikipedia.org / invasive species 